\title{
Electrical Properties of Tuff from the ESF as a Function of Water Saturation and Temperature
}

\author{
J.J. Roberts \\ E. Carlberg \\ W. Lin
}

This is an informal report intended primarily for internal or limited external distribution. The opinions and conclusions stated are those of the author and may or may not be those of the Laboratory.

Work performed under the auspices of the U.S. Department of Energy by the Lawrence Livermore National Laboratory under Contract W-7405-ENG-48. 


\section{DISCLAIMER}

This document was prepared as an account of work sponsored by an agency of the United States Government. Neither the United States Government nor the University of California nor any of their employees, makes any warranty, express or implied, or assumes any legal liability or responsibility for the accuracy, completeness, or usefulness of any information, apparatus, product, or process disclosed, or represents that its use would not infringe privately owned rights. Reference herein to any specific commercial product, process, or service by trade name, trademark, manufacturer, or otherwise, does not necessarily constitute or imply its endorsement, recommendation, or favoring by the United States Government or the University of California. The views and opinions of authors expressed herein do not necessarily state or reflect those of the United States Government or the University of California, and shall not be used for advertising or product endorsement purposes.

This report has been reproduced directly from the best available copy.

Available to DOE and DOE contractors from the Office of Scientific and Technical Information P.O. Box 62, Oak Ridge, TN 37831

Prices available from (423) 576-8401

Available to the public from the National Technical Information Service

U.S. Department of Commerce 5285 Port Royal Rd. Springfield, VA 22161 


\section{Electrical Properties of Tuff From the ESF as a Function of Water Saturation and Temperature Jeffery J. Roberts, Eric Carlberg, and Wunan Lin \\ Lawrence Livermore National Laboratory January 15, 1998}

\section{Introduction}

The electrical properties of partially saturated tuff provide information about the microstructure of the matrix and how water is distributed within the pore space as the material undergoes saturation and desaturation cycles. Understanding electrical properties as a function of saturation and temperature is also important because the determination of water saturation during field tests and laboratory experiments depends on reliable laboratory data. Spatial distribution and temporal variation of moisture content in the rock mass in the repository horizontal is one of the most important parameters needed in order to understand coupled TMHC processes. Geophysical methods are required to determine the moisture content in rock masses during thermal tests. These data are currently used in the inversion of electrical resistance tomography (ERT) and ground penetrating radar (GPR) measurements at the LBT, SHT, and the DST tests. This paper contains a description of the experimental procedure, sample preparation, data collection, and data analyses for tuff samples from the ESF.

Measurements were made at 35,50 , and $70^{\circ} \mathrm{C}$. Additional measurements at $95^{\circ} \mathrm{C}$ are in progress. The range of saturation varied from 0 to near $100 \%$. A paper describing procedures and previous work was presented at the 1994 International High Level Radioactive Waste Management Conference (UCRL-JC-114784). Previous electrical properties of tuff from several NTS boreholes as functions of saturation and temperature are reported by Roberts and Lin (1997). This paper also discusses the frequency dependence of impedance measurements and how the observed electrical responses might relate to microstructure and other transport properties.

\section{Experimental Procedure}


A detailed description of the experimental procedure is found in Roberts and Lin (1994 and 1997). Briefly, electrical resistivity and dielectric permittivity were measured as a function of frequency $\left(10^{-3}\right.$ to $\left.10^{6} \mathrm{~Hz}\right)$. Measurements made over a range of frequency verify measurements made at a single frequency and provide additional information about conduction mechanisms and microstructural parameters. Resistivity measurements are reported for one frequency, $1 \mathrm{kHz}$, as this frequency was determined to be free of electrode contamination (contact impedance) and represents the electrical properties of the material. Dielectric permittivity measurements are reported at $1 \mathrm{MHz}$, the highest frequency of our measurement.

Samples were prepared from cores obtained from chemistry boreholes (CHE-6, CHE-7, CHE-10). Samples with obvious large cavities and inhomogeneous inclusions were avoided. The porosity of each sample was determined by subtracting the dry density from the saturated density and dividing by the water density. Table 1 shows the sample ID, borehole, depth, wet and dry densities, and properties of the samples used. Average properties are listed at the bottom of the table; the average porosity is $9.6 \pm 1.8 \%$. The samples are disk-shaped, with a diameter to thickness aspect ratio of $\geq 10: 1$ (dime shaped). The diameter of the samples is $\sim 5.1 \mathrm{~cm}$. All samples were prepared with the bedding direction perpendicular to the direction of measurement.

Measurements began on samples that were dry. Water from well $\mathrm{J}-13$ was added to the samples in small amounts and allowed to distribute throughout the sample. The length of time for this to occur was typically 3 to 4 hours as verified by examining the resistivity of a sample as a function of time. Saturations were determined by weighing the samples immediately after electrical measurements were completed. Each sample was placed in a custom built holder made of Lucite or Lexan and separated from the atmosphere by an o-ring seal. Despite these precautions, water was sometimes lost from samples when measurements at relatively high saturations were attempted at 50 and $70^{\circ} \mathrm{C}$. The holders were placed in a standard oven and allowed time to equilibrate to the temperature (typically overnight). Temperature was measured at three points inside the oven using type $\mathbf{J}$ thermocouples placed in aluminum blocks. The temperatures were the same at each point to within $+/-3^{\circ} \mathrm{C}$, but were usually within $+/-1.5^{\circ} \mathrm{C}$. 
Upon reaching maximum saturation, the drying portion of the measurements began. During the drying phase, samples were air dried or dried in an oven at $35^{\circ} \mathrm{C}$. The maximum saturation achieved was between 95 and 100\%. Some sample damage in the form of chipping and cracking occurred because of the cooling and heating that was necessary when a sample was taken out of the oven, removed from its holder, weighed, saturated/dried, and placed back in its holder and into the temperature controlled oven. Samples were reshaped when necessary and the holders modified to accept the new shape. Samples were no longer used when it was determined that the electrical properties measurements were unreliable.

\section{Results and Discussion}

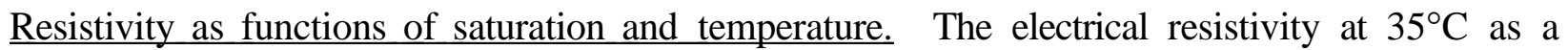
function of saturation is plotted in Figure 1. Only the drying curve is shown for $35^{\circ} \mathrm{C}$, but both wetting and drying are plotted for 50 and $70^{\circ} \mathrm{C}$, which are shown in Figures $2,3,4$, and 5 . This type of resistivity saturation dependence is similar to that observed for other tuff samples. For all temperatures the dry resistivity is between $10^{7}$ and $10^{8} \Omega \mathrm{m}$, and drops rapidly to between $\sim 3000$ and $1000 \Omega \mathrm{m}$ (depending on temperature) as saturation increases. This is interpreted as an indication that the adsorption of water and surface conduction dominates this region of saturation. At $\sim 30 \%$ saturation there is a change in slope of $\log \sigma$ versus saturation. Between 30 and 100\% saturation the resistivity decreases by $1 / 2$ to one order of magnitude.

A small amount of hysteresis is observed between wetting and drying cycles. There are small increases in resistivity during the wetting phase is observed, similar to previous measurements utilizing distilled water as the saturating fluid (Roberts and Lin, 1997). The minimum resistivity in these cases occurs near $80 \%$ saturation. Possible reasons for this minimum are discussed in Roberts and Lin (1997).

Dielectric permittivity as functions of saturation and temperature. The dielectric permittivity is plotted in Figures 6 through 10 and displays features similar to those seen in the resistivity vs. saturation plots. At low saturations the curves are insensitive to temperature. The dry samples all 
have a dielectric constant of between 5 and 6 . At $35^{\circ} \mathrm{C}$ the near saturated sample has a range of values between 22 and 26. This range of dielectric permittivity values at one temperature is fairly typical above $\sim 40 \%$ saturation for all temperatures. The scatter in the data increases as temperature increases, and is particularly bad for the $70^{\circ} \mathrm{C}$ wetting cycle above $\sim 60 \%$ saturation. It is not known why this run shows this scatter. One possible explanation is that capacitance measurement noise at the highest frequencies of measurement (up to $1 \mathrm{MHz}$ ) increases with temperature.

\section{Future work}

Measurements at $95^{\circ} \mathrm{C}$ are in progress. Additional samples are being machined to replace chipped and cracked samples. Measurements performed at $95^{\circ} \mathrm{C}$ on the newer samples that have not previously been subjected to repetitive saturation/desaturation cycles and heating/cooling cycles at 40 and $65^{\circ} \mathrm{C}$ will provide information concerning how important sample history is to these measurements, and how much these cycles change the surface properties of the tuff.

The results will be analyzed in terms of existing mixing model theory and we will attempt to establish relationships that will predict saturation based on electrical properties for the use in geophysical inversions of field data. Upon completion of the $95^{\circ} \mathrm{C}$ data set, we will attempt to establish relationships describing the temperature dependence of resistivity at specific saturations. Water distribution and wetting behavior as a function of saturation will be studied further. 
Table 1. Drift Scale Test samples prepared for electrical properties measurements.

\begin{tabular}{lllccl}
\hline \hline Sample ID & Borehole & Depth, $\mathrm{m}$ & $\begin{array}{c}\text { wet density, } \\
\mathrm{g} / \mathrm{cm}^{3}\end{array}$ & $\begin{array}{c}\text { dry density, } \\
\mathrm{g} / \mathrm{cm}^{3}\end{array}$ & porosity \\
\hline \hline $01002189-2$ & CHE-6 & $43.4-44.1$ & 2.362 & 2.271 & 0.0914 \\
$01002190-2$ & CHE-6 & $63.9-64.6$ & 2.361 & 2.276 & 0.0850 \\
$01002194-2$ & CHE-6 & $99.7-100.4$ & 2.338 & 2.231 & 0.107 \\
$01002200-2$ & CHE-7 & $80.0-80.7$ & 2.372 & 2.284 & 0.0883 \\
$01002205-2$ & CHE-7 & $128.4-129.1$ & 2.382 & 2.296 & 0.0862 \\
$01002206-1$ & CHE-10 & $15.7-16.3$ & 2.359 & 2.258 & 0.101 \\
$01002207-1$ & CHE-10 & $27.3-28.0$ & 2.370 & 2.282 & 0.0876 \\
$01002209-1$ & CHE-10 & $75.6-76.3$ & 2.373 & 2.258 & 0.114 \\
$01002212-2$ & CHE-10 & $91.6-92.3$ & 2.354 & 2.214 & 0.140 \\
$01002215-2$ & CHE-10 & $124.0-124.7$ & 2.330 & 2.248 & 0.0825 \\
\hline mean* & & 10 samples & $2.36 \pm 0.02$ & $2.26 \pm 0.03$ & $0.098 \pm 0.018$ \\
\hline
\end{tabular}

*Statistical mean for 10 samples. Errors represent one standard deviation for all samples collectively. 


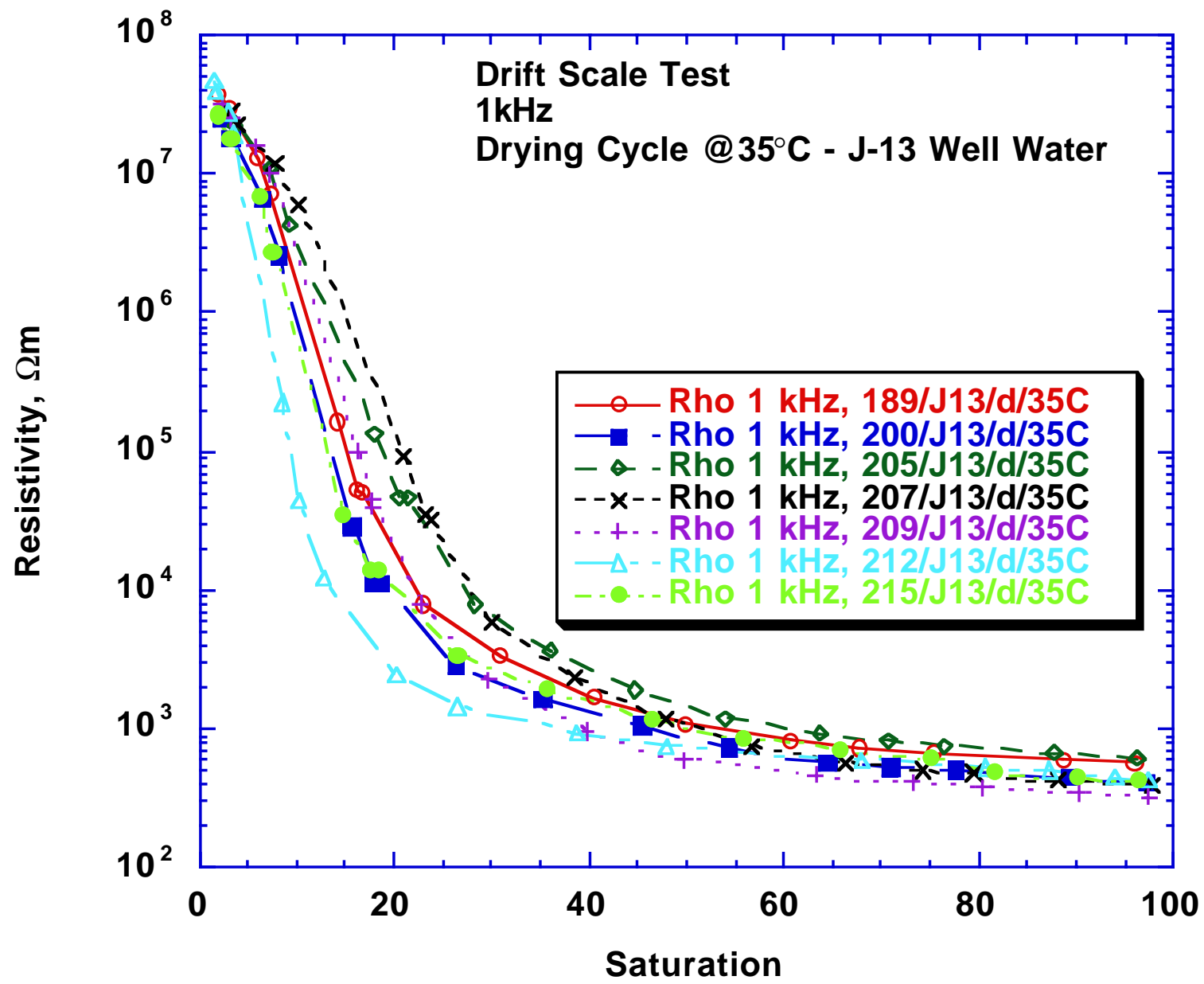

Figure 1. Resistivity as a function of saturation for 7 DST samples at $1 \mathrm{kHz}, 35^{\circ} \mathrm{C}$, drying cycle. 


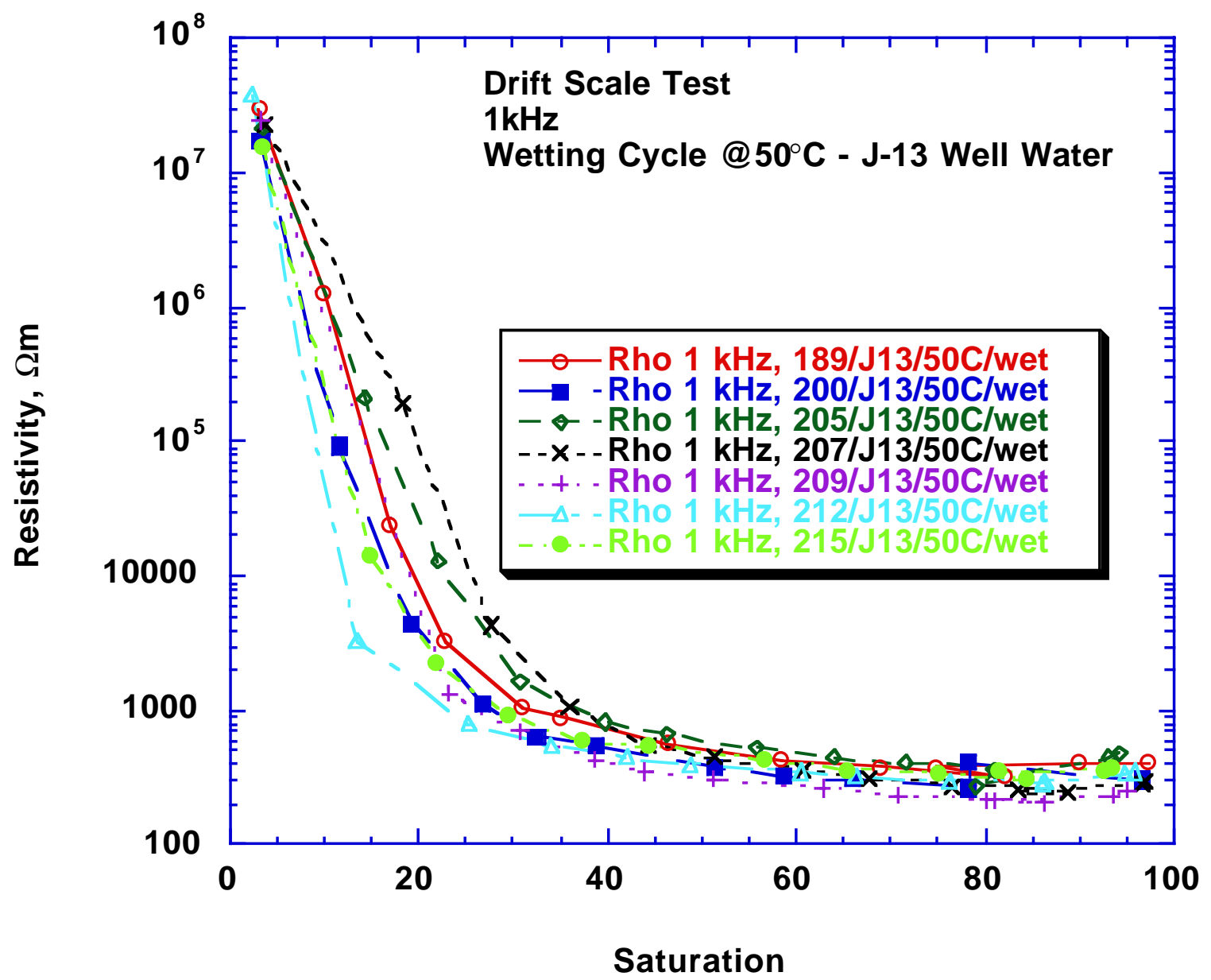

Figure 2. Resistivity as a function of saturation for $7 \mathrm{DST}$ samples at $1 \mathrm{kHz}, 50^{\circ} \mathrm{C}$, wetting cycle. 


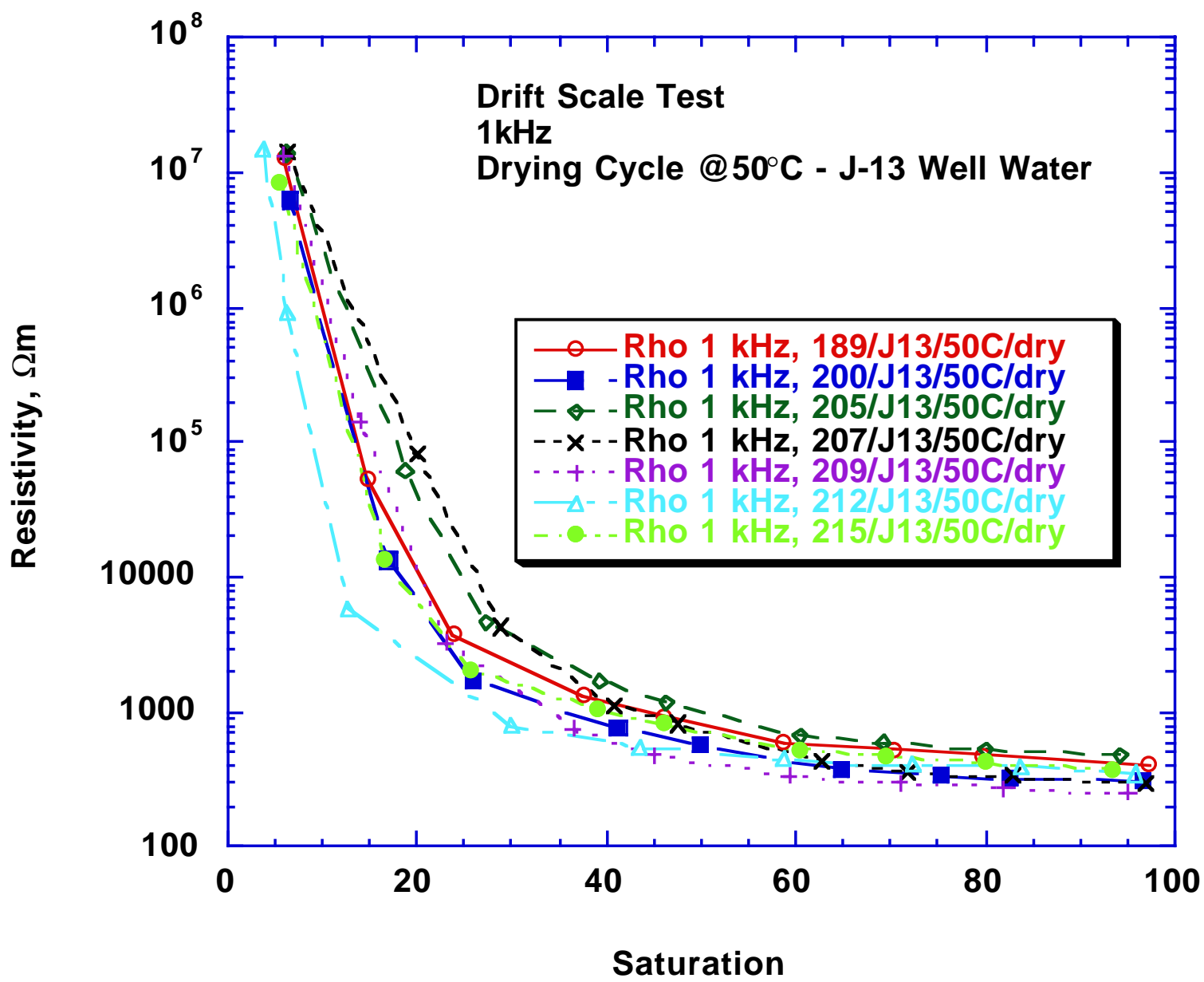

Figure 3. Resistivity as a function of saturation for 7 DST samples at $1 \mathrm{kHz}, 50^{\circ} \mathrm{C}$, drying cycle. 


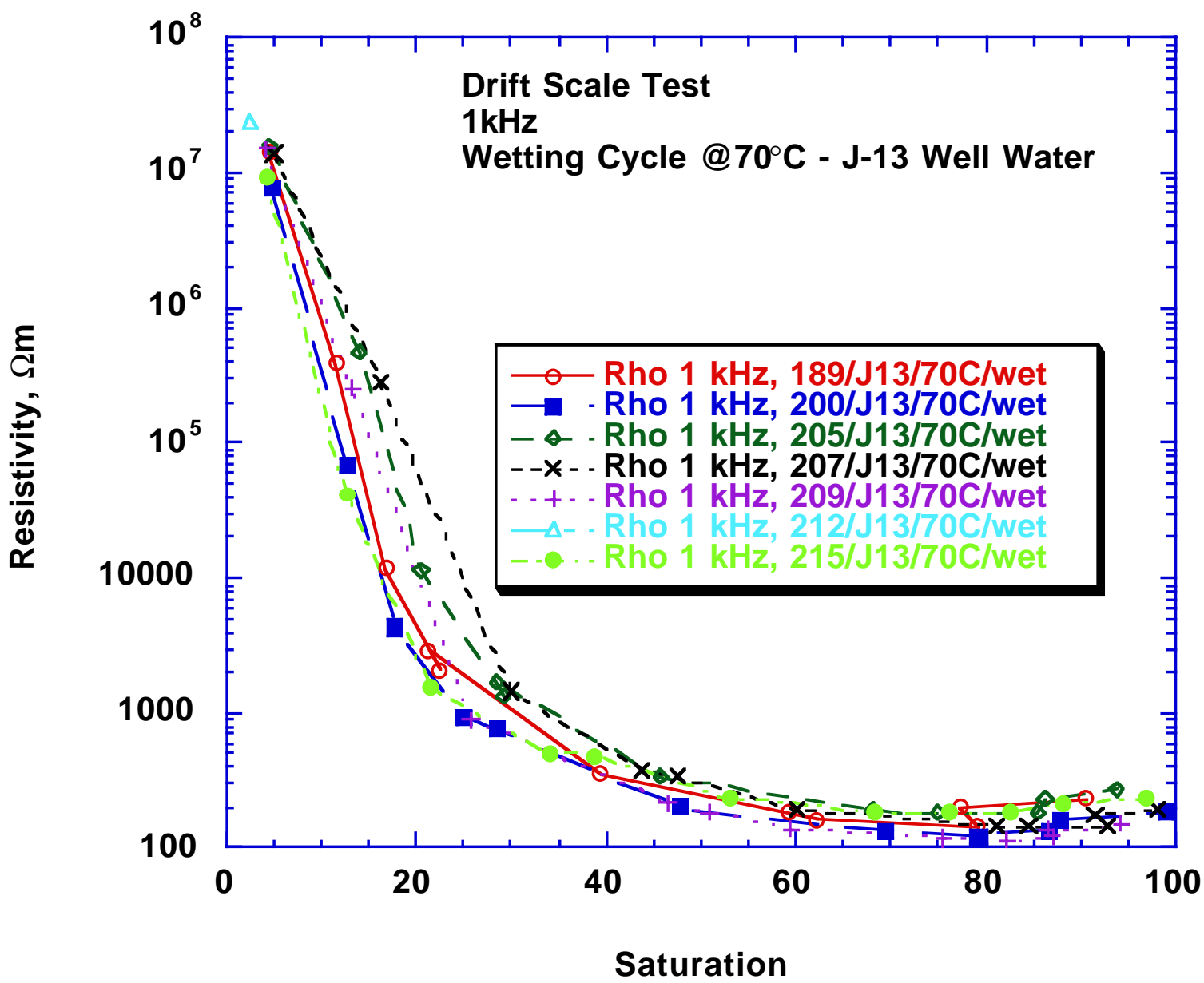

Figure 4. Resistivity as a function of saturation for 7 DST samples at $1 \mathrm{kHz}, 70^{\circ} \mathrm{C}$, wetting cycle. 


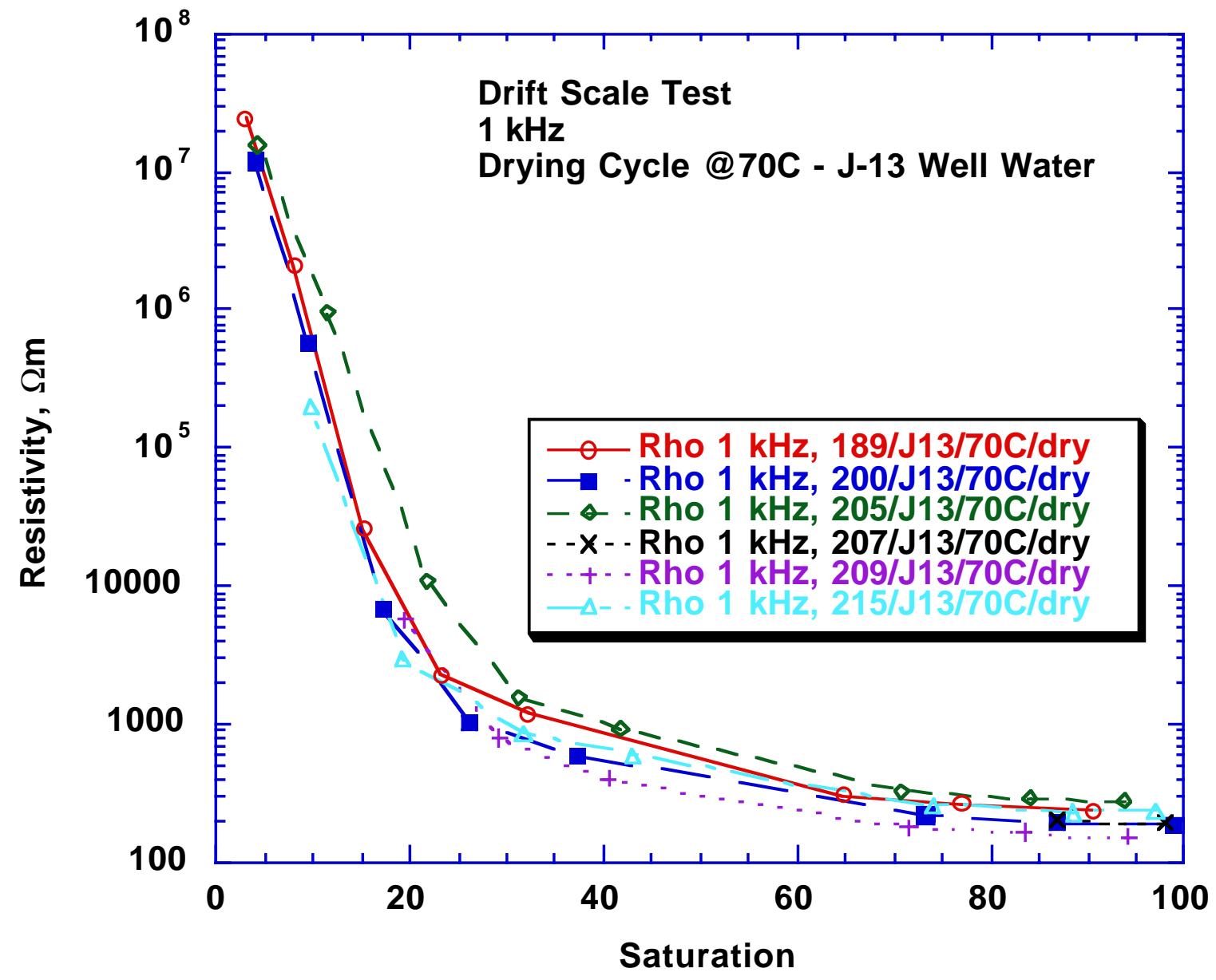

Figure 5. Resistivity as a function of saturation for 6 DST samples at $1 \mathrm{kHz}, 70^{\circ} \mathrm{C}$, drying cycle. 


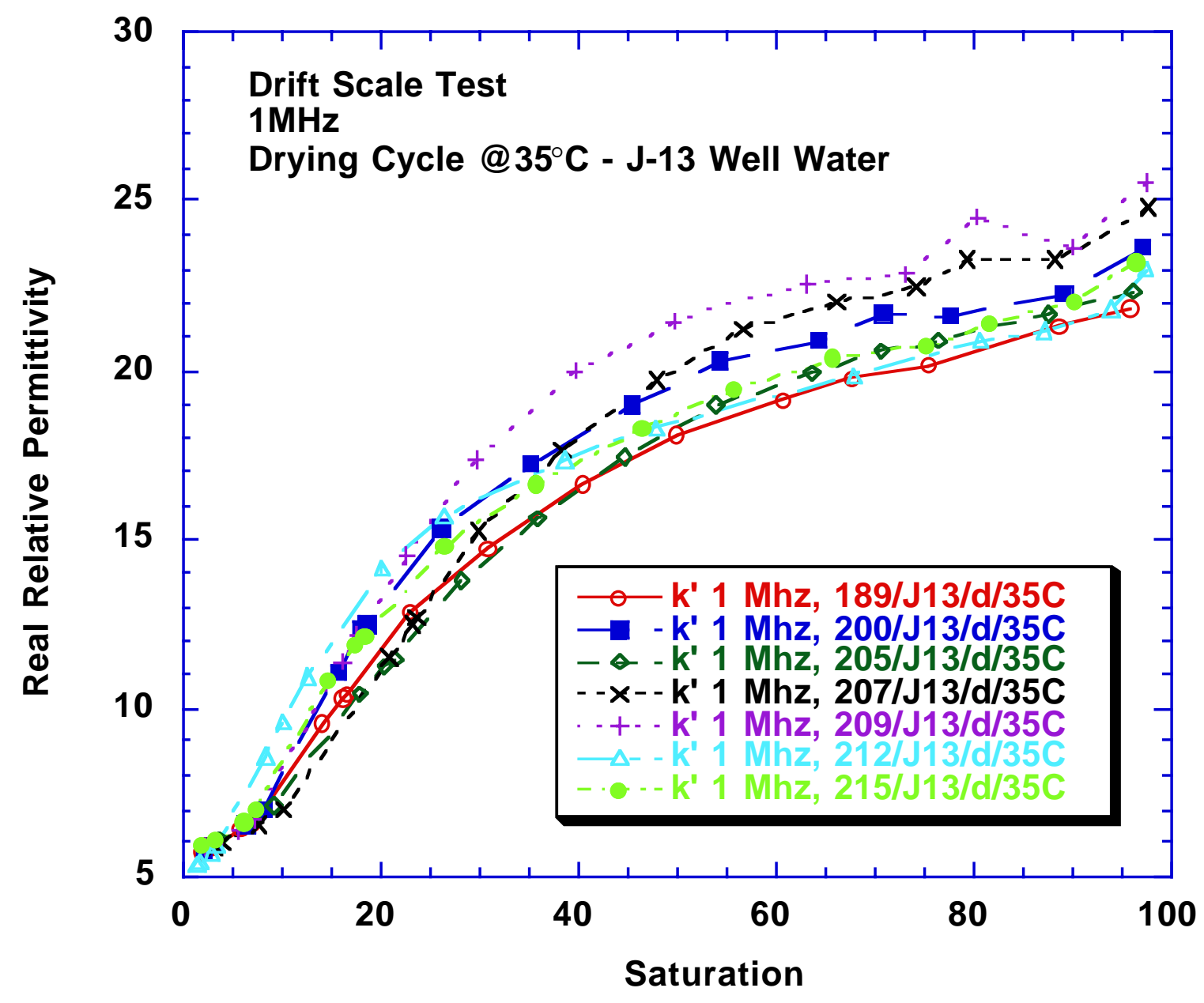

Figure 6. Real relative permittivity as a function of saturation for 7 DST samples at $1 \mathrm{MHz}$, $35^{\circ} \mathrm{C}$, drying cycle. 


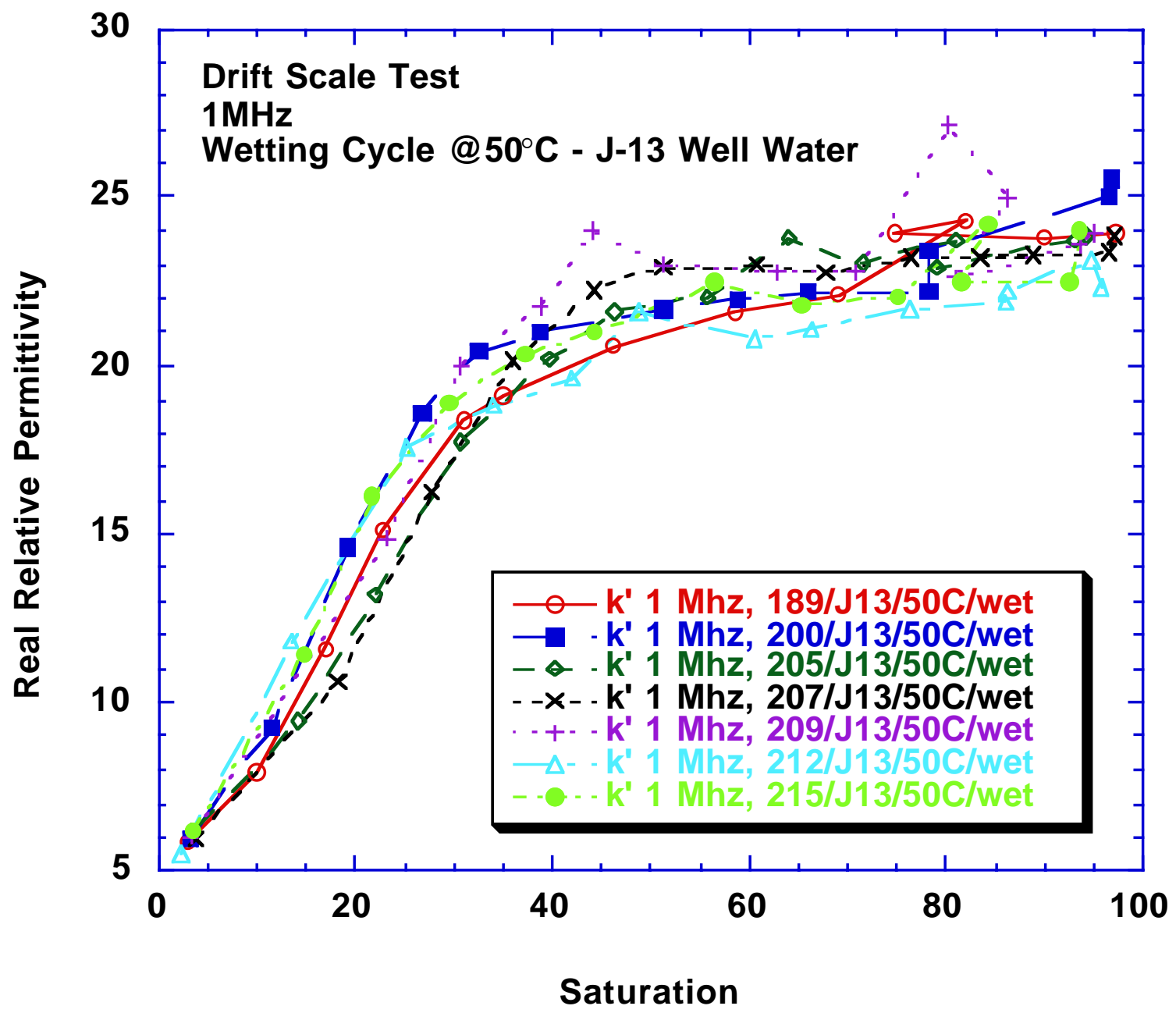

Figure 7. Real relative permittivity as a function of saturation for 7 DST samples at $1 \mathrm{MHz}$, $50^{\circ} \mathrm{C}$, wetting cycle. 


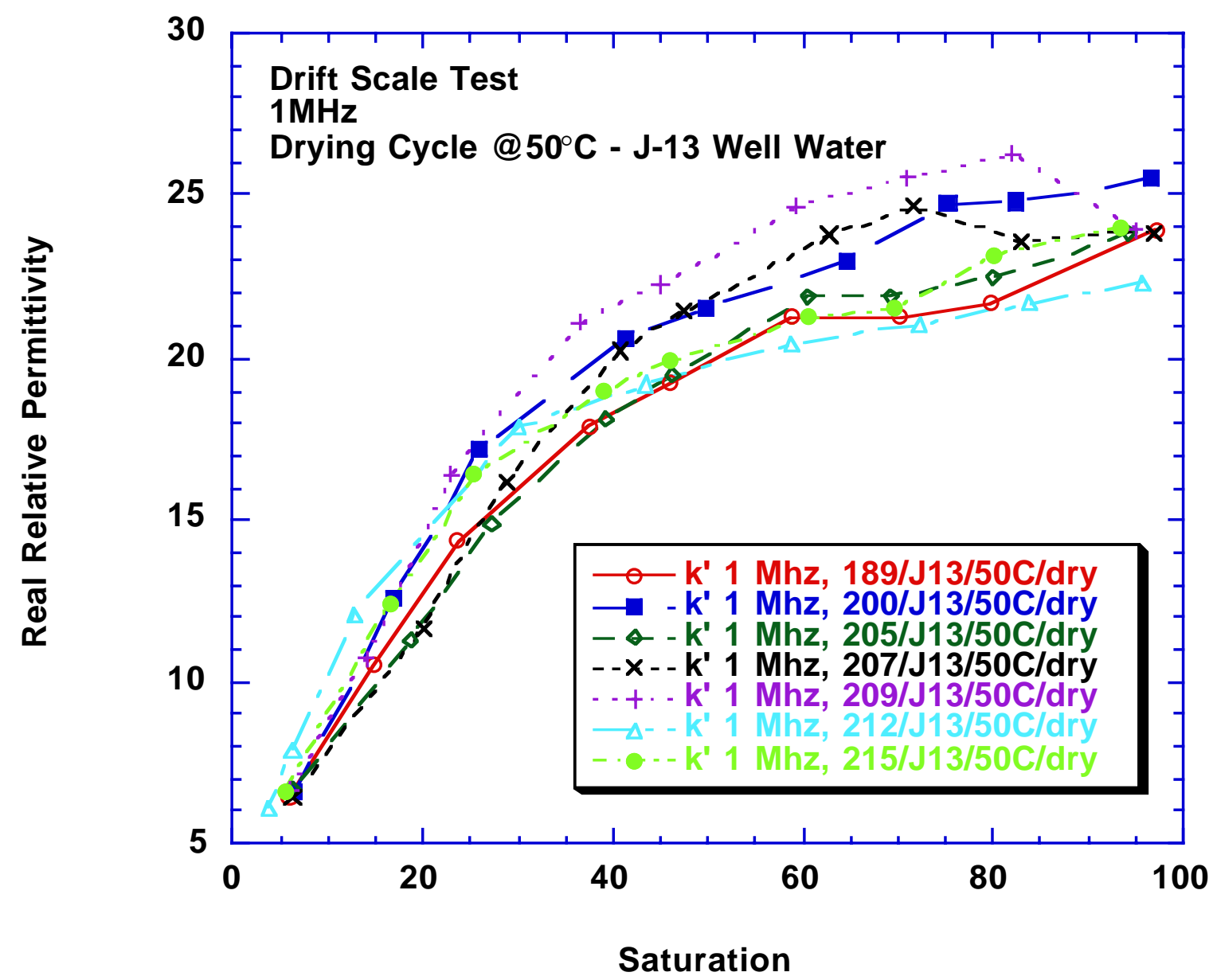

Figure 8. Real relative permittivity as a function of saturation for 7 DST samples at $1 \mathrm{MHz}$, $50^{\circ} \mathrm{C}$, drying cycle. 


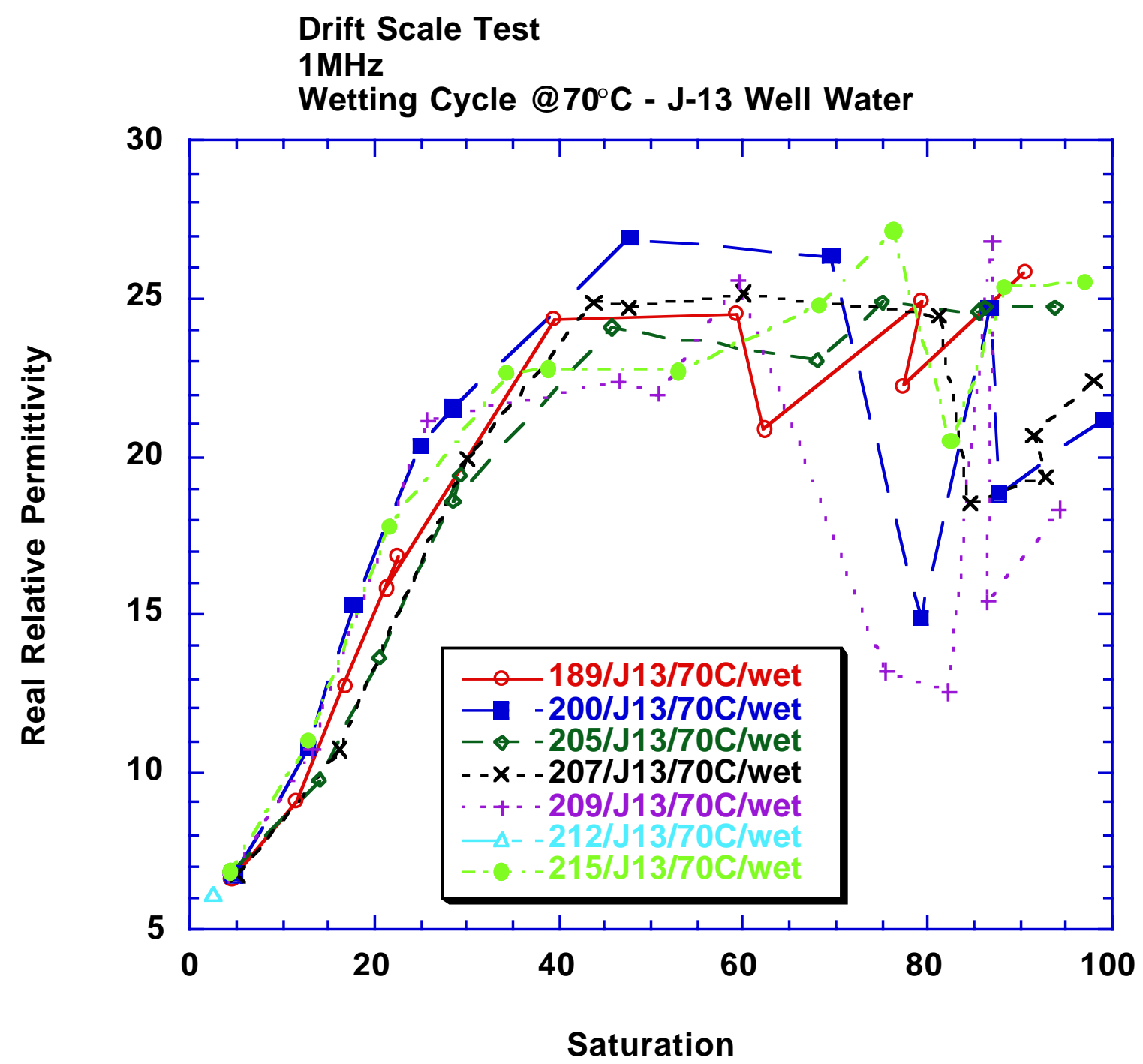

Figure 9. Real relative permittivity as a function of saturation for 7 DST samples at $1 \mathrm{MHz}$, $70^{\circ} \mathrm{C}$, wetting cycle. 


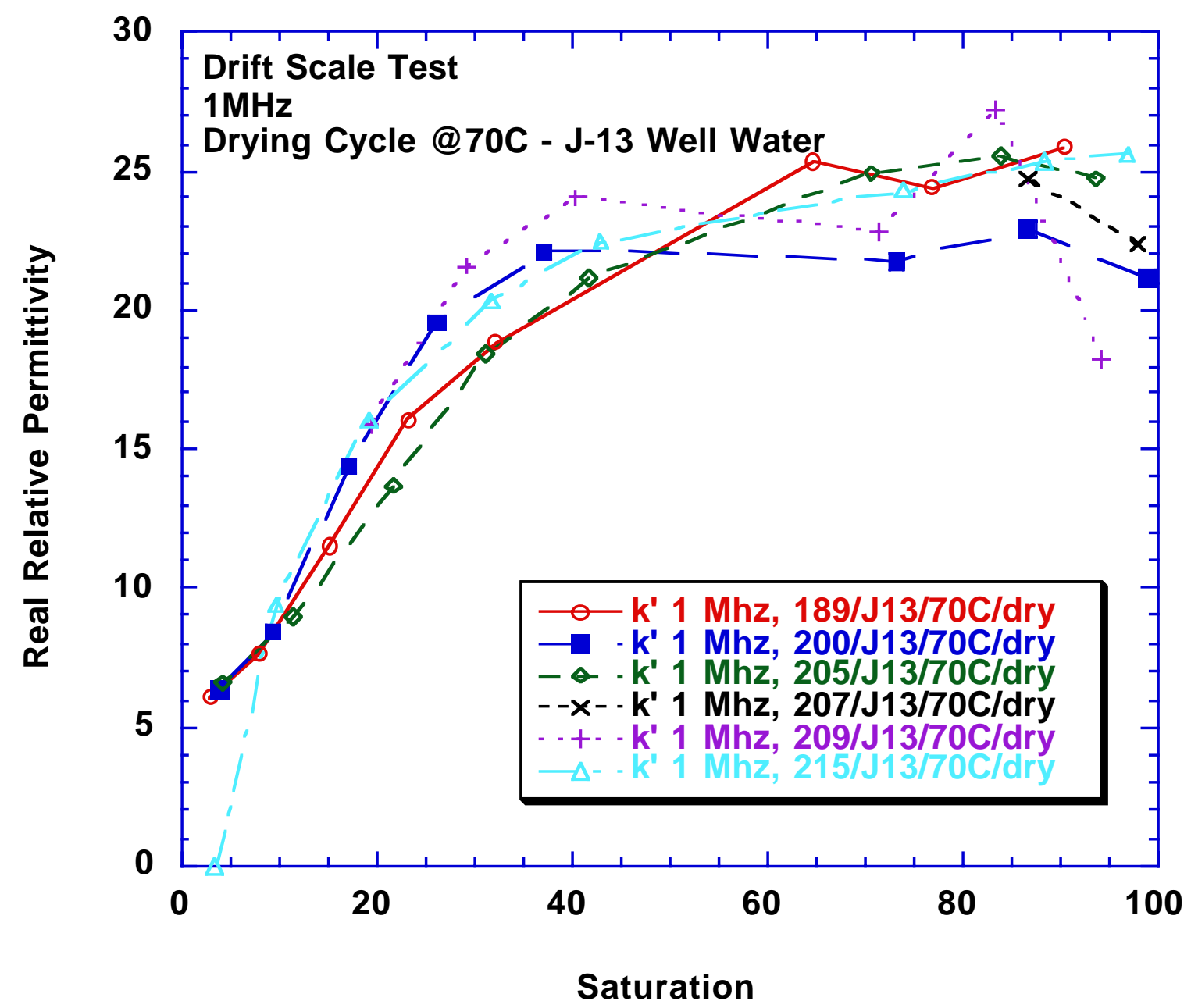

Figure 10. Real relative permittivity as a function of saturation for 6 DST samples at $1 \mathrm{MHz}$, $70^{\circ} \mathrm{C}$, drying cycle.

Acknowledgments. Dave Ruddle and Carl Boro provided technical support. This work was supported by the Yucca Mountain Site Characterization Project. Work performed under the auspices of the US. Department of Energy by Lawrence Livermore National Laboratory under contract W-7405-ENG-48.

\section{References}

Roberts, J.J., and W. Lin, Electrical properties of Topopah Spring Tuff as a function of saturation, Proceedings of the Fifth Annual International Conference on High Level Radioactive Waste Management, Las Vegas, NV, May 22-26, 1994, American Nuclear Society, Inc., LaGrange Park, IL, pp. 2112-2120. NNA 19940524.0018.

Roberts, J.J., and W. Lin, 1997, Electrical properties of partially saturated Topopah Spring Tuff: Water distribution as a function of saturation, Water Resources Res., 33, 577-587. 


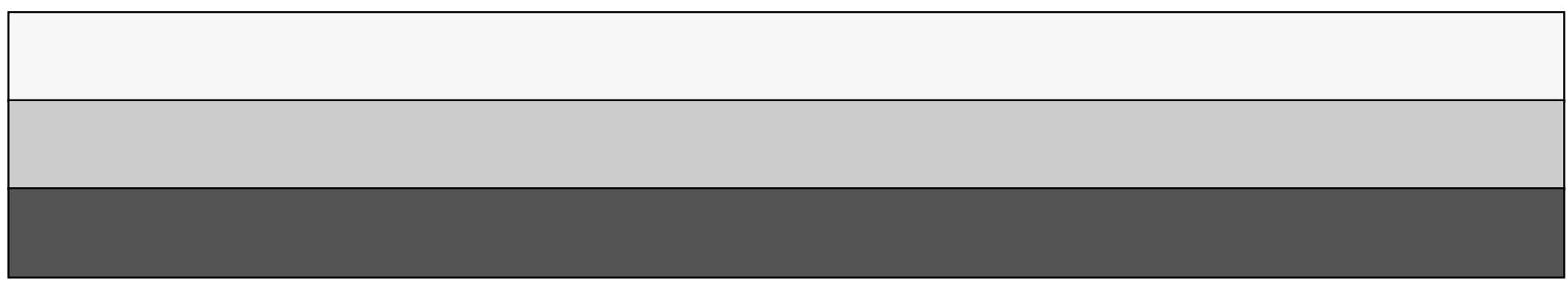

